\title{
Efeitos da ilha de calor nos níveis de conforto em ambientes externos e internos para as condições climáticas de Curitiba
}

\author{
Effects of the urban heat island on outdoor and \\ indoor thermal comfort for the climatic conditions of Curitiba
}

\section{Eduardo Leite Krüger ${ }^{1}$}

口

\begin{abstract}
RESUMO
O crescimento urbano e o decorrente surgimento de ithas de calor são fatores responsáveis não apenas por mudanças nos padrões de conforto e desconforto térmico urbanos mas também por possíveis impactos no aumento da demanda de energia (em climatização artificial) das edificações urbanas. Países em desenvolvimento, a maior parte deles localizada em regiões tropicais, apresentam taxas de crescimento urbano mais elevadas relativamente aos países desenvolvidos; segundo dados da ONU, no período de 2005 - 2010, a taxa de urbanização dos primeiros foi cerca de cinco vezes mais alta que a dos últimos. Nesse contexto, o objetivo do presente trabalho foi analisar a atual ilha de calor urbana de Curitiba, decorrente de seu considerável crescimento urbano nas últimas décadas, a partir de um monitoramento climático contínuo entre dezembro de 2011 e fevereiro de 2013 por meio de estações meteorológicas localizadas na mancha urbana. Adicionalmente à análise de diferenças na temperatura local, quantificaram-se níveis de conforto/desconforto térmico a fim de se verificar o efeito integrado das diversas variáveis meteorológicas em termos de percentuais de horas em frio, conforto e calor, e suas variações dentro e fora da área urbana. Complementarmente são analisadas implicações da ilha de calor urbana em níveis de conforto em ambientes internos. Verificou-se que a presença de uma ilha de calor naárea urbana para combater o frio no inverno acarreta aumento desproporcional do calor em situação de verão, não havendo benefício térmico de maneira geral.
\end{abstract}

Palavras-chave: crescimento urbano; illha de calor; conforto térmico; habitação de interesse social.

\begin{abstract}
Urban growth and the resulting urban heat island effect are not only responsible for variations in thermal comfort and discomfort levels within the city but also for increases in building energy demand for air conditioning. In tropical regions, urbanization rates tend to be the highest: the average annual rate of change of the urban population for the five-year period 2005 - 2010 was just over five times higher in the less developed regions than in the more developed part of the world, following a rising trend. The purpose of this paper was to analyze the urban heat island of Curitiba, which results from its considerable urban growth over the last decades, by means of a long-term climate monitoring between December 2011 and February 2013 with a pair of weather stations within the urban area. Additionally, an analysis was performed with regard to outdoor comfort, so that the combined effect of relevant meteorological variables could be assessed in terms of percentages of cold, comfortable and hot hours and variations in and outside the urban area. Finally, implications of the urban heat island effect on indoor conditions are analyzed. It is concluded that the heat island effect with reductions of cold stress in winter does not offset the occurrence of excess heat in summer, with an overall not advantageous effect
\end{abstract}

Keywords: urban growth; urban heat island; thermal comfort; social housing

\section{INTRODUÇÃO}

A relação entre urbanização e surgimento de ilhas de calor (diferenças de temperaturas entre a área urbana e as áreas rurais no entorno) é apontada por vários autores como consequência natural do processo de crescimento urbano. Nesse ponto, Oke (1978) discute a relação direta entre tamanho de

cidades diversas em termos populacionais e a intensidade da ilha de calor, mostrando haver uma relação direta entre porte da cidade e aumento da magnitude da ilha de calor urbano.

Atualmente, as taxas de urbanização apresentam uma tendência crescente em diversos locais do planeta, sendo mais elevadas em regiões em desenvolvimento comparativamente às regiões desenvolvidas,

$\square$

'Departamento de Construção Civil, Universidade Tecnológica Federal do Paraná (UTFPR) - Curitiba (PR), Brasil.

Endereço para correspondência: Eduardo Leite Krüger - Rua Deputado Heitor Alencar Furtado, 4900 - 81280-340 - Curitiba (PR), Brasil - E-mail: ekruger@utfpr.edu.br Recebido: 08/11/13 - Aceito: 12/11/15 - Reg. ABES: 126270 
mantendo uma diferença cinco vezes mais alta entre ambas as regiões na metade do século XXI (ONU, 2012). Considerando o fato de que grande parte das regiões em desenvolvimento se situa em regiões tropicais, a definição de políticas de planejamento urbano que norteiem um crescimento ordenado do ponto de vista microclimático assume grande importância.

No Brasil, a maior parte das cidades cresceu de forma desordenada, agravando assim a deterioração do ambiente. A intensidade da ilha de calor em São Paulo, por exemplo, quantificada na década de 1980 , aponta diferenças de $10^{\circ} \mathrm{C}$ entre áreas urbanas e rurais, particularmente em áreas mais poluídas e adensadas na cidade (LOMBARDO, 1985).

Como uma das poucas exceções, Curitiba contou com um processo permanente e institucionalizado de planejamento urbano, desde 1943, com o "Plano Agache". Porém, a mecanização do campo na década de 1970, associada à criação da Cidade Industrial de Curitiba (CIC), atraiu grande número de imigrantes em busca de oportunidades de trabalho. O movimento migratório foi realimentado na década de 1990, impulsionado pelo eficiente city marketing municipal e pela vinda de empresas montadoras de automóveis, induzindo a um crescimento acelerado de Curitiba e dos municípios circunvizinhos. O modelo de planejamento urbano que vinha sendo realizado até então mostrou-se limitado em relação aos inúmeros problemas socioambientais evidenciados: ocupações irregulares em áreas de mananciais hídricos da região, inundações cada vez mais frequentes, desconforto ambiental e poluição atmosférica agravada pelo desenho urbano e pela organização espacial da região intensamente urbanizada, entre outros efeitos (DUMKE, 2007).

Dessa forma, o desenvolvimento urbano resultou em uma cidade na qual se destacam não só as áreas verdes, o sistema viário, a variação da localização das indústrias ao longo do tempo, mas também a diversidade socioespacial das habitações, ocasionando problemas socioambientais. Sua configuração espacial se caracteriza hoje principalmente pela maciça verticalização ao longo das Vias Estruturais, que transformou de forma radical o sistema urbano polinucleado preexistente, acarretando um importante impacto na paisagem urbana e nos aspectos do conforto ambiental. Margeando os Eixos Estruturais criados para direcionar o crescimento da cidade e o fluxo de veículos, o zoneamento proporcionou a construção de edifícios em altura que formam cânions urbanos, alterando os campos térmicos (MINELLA et al., 2011), a iluminação natural (SUGA \& KRÜGER, 2009), a ventilação e a qualidade do ar (MINELLA et al., 2011).

Implicações da ilha de calor nos ambientes internos foram exploradas em clima temperado, por Emmanuel e Krüger (2012), em estudo sobre a ilha de calor de Glasgow, Escócia, e em Londres, onde foram verificadas reduções de 65 a $85 \%$ na carga térmica de aquecimento, para localidades mais centrais relativamente a localidades fora da malha urbana, com a demanda por resfriamento aumentando em 32 a 42\% no centro da cidade (GRIMMOND, 2011).

Nesse contexto, o presente trabalho visou analisar se a ilha de calor urbana traria algum benefício térmico para a área urbana, considerando as condições climáticas de Curitiba, a capital mais fria do país. A partir disso, investigou-se ainda a ilha de calor urbana de Curitiba e suas consequências em níveis de conforto em espaços externos e internamente a moradias populares.

\section{METODOLOGIA}

Este trabalho foi realizado em quatro partes:

1. Monitoramento microclimático durante (abrangendo estações do ano e diversos tipos de tempo).

2. Comparação das intensidades da ilha de calor urbana verificadas por período (estações do ano, períodos específicos) com identificação dos maiores valores e frequência de ocorrência.

3. Análise dos efeitos de cada período na sensação térmica predita ao nível do pedestre/consequências nos níveis de conforto/desconforto em espaços abertos.

4. Implicações no nível interno em habitações populares.

\section{Clima local}

Situada em uma latitude de $25.5^{\circ} \mathrm{S}$, longitude $49^{\circ} \mathrm{W}$ e altitude aproximada de 917 m acima do nível do mar, Curitiba e sua Região Metropolitana apresentam tipo climático predominantemente mesotérmico com verão fresco $(\mathrm{Cfb})$, segundo a classificação de Koeppen, ou clima subtropical de altitude. A área urbana caracteriza um clima urbano-regional particular, pois forma uma ilha de frescor em relação às cidades vizinhas, em razão do efeito do relevo associado à dinâmica atmosférica. A formação de tipos de tempo quente na área deve-se a dois dos três sistemas atmosféricos dominantes e de origem tropical (Massa Tropical Atlântica (MTa) e Massa Tropical Continental (MTc) e esporadicamente a Massa Equatorial Continental (MEc)), que reforçam o efeito da latitude local. As frequentes baixas temperaturas regionais e locais ocorrem em razão do sistema extratropical (Massa Polar Atlântica (Mpa)), que se associa ao efeito da altitude.

Embora a temperatura média das máximas esteja em torno dos $20^{\circ} \mathrm{C}$ no verão, as temperaturas absolutas podem aproximar-se $\operatorname{dos} 40^{\circ} \mathrm{C}$. No inverno, as temperaturas atingem inúmeras vezes valores negativos, principalmente ao Sul da região metropolitana, situando-se a média das temperaturas mínimas em torno de $13^{\circ} \mathrm{C}$. A área apresenta-se com boa umidade o ano todo, com pluviosidade geralmente superior a $1.300 \mathrm{~mm}$ anuais. Destaca-se ainda a variabilidade diária e anual do clima (MENDONÇA \& DUBREUIL, 2005). 


\section{Monitoramento térmico para quantificação da ilha de calor de Curitiba}

Para realização da pesquisa, utilizaram-se dados monitorados pela estação meteorológica do SIMEPAR, localizada no Centro Politécnico da Universidade Federal do Paraná (UFPR), aqui assumida como estação urbana, e uma estação meteorológica implantada na Universidade Tecnológica Federal do Paraná (UTFPR), localizada na região denominada Ecoville, área periurbana, aqui assumida como estação rural. A Figura 1 mostra a posição geográfica das duas estações, tendo a primeira uma localização mais central e a segunda uma localização mais periférica. A distância entre as duas estações é de $12 \mathrm{~km}$, aproximadamente.

A "Estação Ecoville" da marca HOBO (modelo H21-00) foi implementada em dezembro de 2011 e estava equipada com um sensor de temperatura e umidade (S-THB-M002); piranômetro de silício (S-LIB-M003) e anemômetro (S-WCA-M003). Está localizada sobre a cobertura de um dos prédios da UTFPR sobre laje de concreto, desobstruída de edificações, segundo procedimentos apresentados por Oke (2006). Não há fontes de calor antropogênico significativas no entorno.

A “Estação SIMEPAR" (automática) foi implantada em 1997, e os instrumentos adotados pelo SIMEPAR são: barômetro Sutrom Accubar (Modelo 5600-0120); piranômetro (LI-COR Radiation Sensor e LI-200 SA Pyranometer Sensor com detector fotovoltaico de alta estabilidade); termo-higrômetro (Sutron Relative Humidity and Air Temperature Probe, Modelo 5600-0313-1) e anemômetro (Young Meteorological Instruments, Modelo 05103). A Estação SIMEPAR situa-se no Centro Politécnico da Universidade Federal do Paraná, em área urbanizada no município pólo da Região Metropolitana de Curitiba, e encontra-se instalada em uma superfície gramada na entrada do campus universitário, parte mais elevada do terreno. As poucas obstruções à radiação solar direta e difusa são as pequenas construções próximas, além de poucas árvores esparsas localizadas

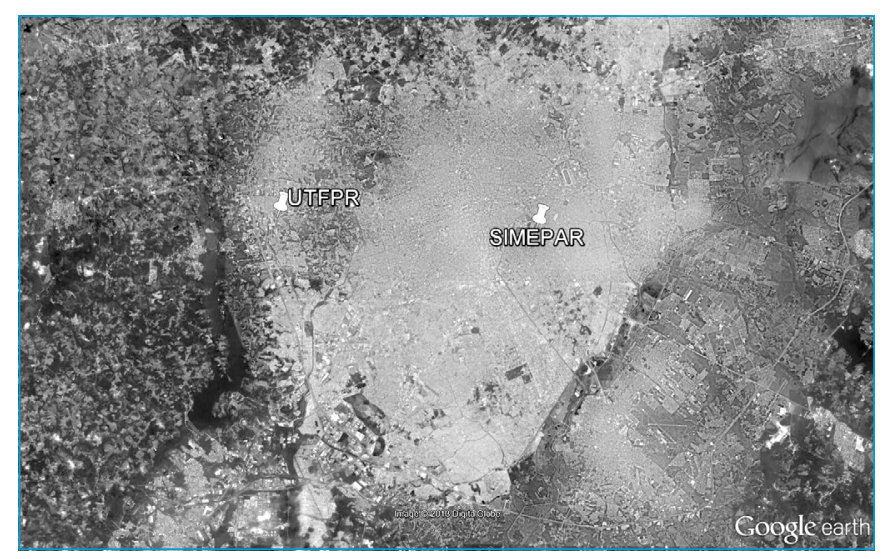

Fonte: Google Earth (imagem de satélite obtida em 7 de julho de 2009).

Figura 1 - Localização das estações analisadas. principalmente no lado sul da estação. A BR-277, que se encontra a uma distância aproximada de $50 \mathrm{~m}$ da estação, constitui importante fonte de calor antropogênico.

A Tabela 1 mostra o período de monitoramento das variáveis climáticas em cada local, ocorrido de 16 de dezembro de 2011 a 19 de fevereiro de 2013, com algumas falhas em decorrência da perda de dados. A mesma tabela mostra a definição adotada para as estações do ano.

A análise da ilha de calor foi realizada a partir das diferenças térmicas encontradas entre ambas as estações, para o período completo e para diferentes estações do ano. Definiram-se para cada situação períodos diurnos e noturnos. A fim de desconsiderar os períodos de transição entre noite e dia, foram desconsideradas duas horas em torno dos horários de nascer e pôr do sol, determinados matematicamente segundo dia do ano, declinação magnética e latitude local, conforme metodologia sugerida por Szokolay (1983).

\section{Procedimento adotado para análise de graus de conforto/desconforto térmico}

Para a análise de graus de conforto/desconforto no espaço externo, foi utilizado um modelo de conforto em espaços abertos desenvolvido para Curitiba por Rossi (2012). Para geração do modelo adotado neste trabalho, Rossi procedeu a um monitoramento de dados meteorológicos com levantamento simultâneo de sensação e preferência térmicas com transeuntes na zona de pedestres de Curitiba, a partir da aplicação de questionários de conforto. Os questionários de conforto aplicados seguiram a norma ISO 10551 (1995), envolvendo questões relativas à sensação térmica dos transeuntes, contabilizando pouco mais de 2.024 questionários respondidos.

Tabela 1 - Conjunto de dados analisados, por períodos monitorado.

\begin{tabular}{|c|c|c|}
\hline Período & Datas/intervalos & n (dias) \\
\hline \multirow{5}{*}{ Período completo } & 16/12/2011 a 23/01/2012 & \multirow{5}{*}{387} \\
\hline & 26/01/2012 a 19/02/2012 & \\
\hline & 21/02/2012 a 24/05/2012 & \\
\hline & 30/06/2012 a 15/02/2013 & \\
\hline & 17/02/2013 a 19/02/2013 & \\
\hline \multirow{5}{*}{ Períodos de verão } & 21/12/2011 a 23/01/2012 & \multirow{5}{*}{147} \\
\hline & 26/01/2012 a 19/02/2012 & \\
\hline & 21/O2/2012 a 20/03/2012 & \\
\hline & 21/12/2012 a 15/02/2013 & \\
\hline & 17/02/2013 a 19/02/2013 & \\
\hline Período de inverno & 30/06/2012 a 22/09/2012 & 83 \\
\hline \multirow{4}{*}{ Períodos de primavera } & 16/12/2011 a 20/12/2011 & \multirow{4}{*}{92} \\
\hline & 24/09/2012 a 14/10/2012 & \\
\hline & 16/10/2012 a 07/12/2012 & \\
\hline & 09/12/2012 a 21/12/2012 & \\
\hline Período de outono & 22/03/2012 a 25/05/2012 & 65 \\
\hline
\end{tabular}


A partir dessa base de dados, Rossi (2012) agrupou os dados de percepção térmica segundo três categorias, definidas a partir da associação dos votos de percepção e preferência térmica, da seguinte forma:

- Grupo 1: desconforto para o frio (voto de percepção $<0$ associado ao voto de preferência $>0$ ).

- Grupo 2: conforto (percepção $=0$ e preferência $=0$ ).

- Grupo 3: desconforto para o calor (percepção > 0 associado à preferência $<0)$.

Foi desenvolvido a partir disso um modelo de predição cuja variável dependente é a sensação térmica, segundo as três categorias citadas acima, ou seja, desconforto para o frio, conforto e desconforto para o calor, e cujas variáveis independentes são as condições meteorológicas monitoradas. No modelo final desenvolvido, utilizam-se variáveis comumente registradas em estações meteorológicas oficiais, quais sejam: temperatura (Ta) e umidade relativa do ar (UR), velocidade do vento (Va) e radiação solar global em plano horizontal (RS), de modo a tornar o modelo aplicável a análises diversas no campo da biometeorologia.

O modelo preditivo desenvolvido por Rossi (2012) utilizou-se da técnica da análise discriminante linear denominada Função Discriminante Linear (FDL), que é uma das técnicas adequadas quando a única variável dependente é categórica, sendo aplicada em casos nos quais a amostra pode ser dividida em grupos, com base na variável dependente categórica, permitindo a elaboração de uma função matemática. Dessa forma, obteve-se $\mathrm{k}=3$ grupos (desconforto para o frio, conforto e desconforto para o calor) e $\mathrm{m}=4$ variáveis independentes (Ta, UR, Va, RS), o que resultou em três funções discriminantes, cada uma com quatro variáveis.

\section{Procedimento adotado para análise de graus de conforto/desconforto em ambientes internos}

Para avaliar os efeitos da ilha de calor em ambientes internos, ou seja, na temperatura interna de edificações, adotou-se um método de estimativa para uma base de dados gerada pelos autores durante a pesquisa de Dumke (2002). Os dados referem-se a temperaturas internas medidas em habitações de interesse social localizadas em Curitiba, a partir do monitoramento simultâneo de 18 moradias habitadas e com sistema construtivo diferenciado, como mostra a Tabela 2 .

As moradias foram monitoradas durante o inverno de 2000 e no verão de 2001, e apresentavam valores de transmitância e atraso térmicos variados, os quais foram responsáveis por diferentes níveis de desempenho térmico. Os valores calculados de transmitância térmica variaram entre 1,0 e $5,3 \mathrm{~W} \cdot \mathrm{m}^{-2} \cdot{ }^{\circ} \mathrm{C}^{-1}$ (paredes) e $0,7 \mathrm{e}$ $2,3 \mathrm{~W} \cdot \mathrm{m}^{-2} \cdot{ }^{\circ} \mathrm{C}^{-1}$ (cobertura); os valores de atraso térmico variaram entre 0,9 e $5,1 \mathrm{~h}$ (paredes) e 0,6 e 7,1 h (cobertura). Internamente, posicionou-se um equipamento registrador de temperatura no centro da moradia e, externamente, utilizou-se equipamento idêntico, devidamente protegido de radiação solar direta e de chuvas.

A partir da base de dados coletadas durante a pesquisa de Dumke (2002), traçaram-se relações entre temperaturas interna e externa, obtendo-se diferenças térmicas médias por períodos (diurno e noturno) e para cada estação (verão e inverno), para cada moradia individualmente.

As diferenças térmicas encontradas permitem estimar o efeito da localização da moradia, adicionando-se ou subtraindo-se a diferença encontrada entre o exterior e interior da moradia aos valores medidos no meio urbano versus rural, ou seja, na Estação SIMEPAR e na Estação Ecoville. Com isso, pode-se inferir sobre os níveis de conforto nessas moradias advindos de sua localização. Considerando-se que grande parte das moradias monitoradas mostrou maior uso durante a noite (conforme informado pelos moradores), avaliou-se especificamente a condição noturna quanto aos níveis de conforto atingidos nos ambientes internos.

A referência adotada para analisar-se a adequação de cada moradia foi realizada segundo os critérios apresentados por Peeters et al. (2009). Segundo esses autores, a temperatura de neutralidade térmica (Tn) no dormitório pode ser estimada em função da temperatura externa $(\mathrm{Te}) 1$, da seguinte forma:

$\begin{array}{ll}\mathrm{Tn}=16^{\circ} \mathrm{C} & \text { para } \mathrm{Te}<0^{\circ} \mathrm{C} \\ \mathrm{Tn}=0,23 \mathrm{Te}+16 & \text { para } 0^{\circ} \mathrm{C} \leq \mathrm{Te}<12,6^{\circ} \mathrm{C} \\ \mathrm{Tn}=0,77 \mathrm{Te}+9,18 & \text { para } 12,6 \leq \mathrm{Te}<21,8^{\circ} \mathrm{C} \\ \mathrm{Tn}=26^{\circ} \mathrm{C} & \text { para } \mathrm{Te} \geq 21,8^{\circ} \mathrm{C}\end{array}$

Para este trabalho, foram calculadas então, para cada período de ocupação (verão e inverno) e para cada moradia, as temperaturas internas referenciais de conforto segundo as equações apresentadas, verificando-se as diferenças para cima (calor) e para baixo (frio) desse patamar, conforme a localização (situação urbana ou situação rural).

\section{RESULTADOS E DISCUSSÃO}

A Tabela 3 mostra resumidamente os valores de temperatura ambiente registrados em cada estação de monitoramento (Estação SIMEPAR versus Estação Ecoville) para o período completo de monitoramento e para as diversas estações do ano.

Nota-se a ocorrência de temperaturas mais baixas na Estação Ecoville (rural ou periurbana) de forma mais evidente nas mínimas absolutas e nas médias das mínimas de cada período, tendo como consequência uma temperatura média ligeiramente mais baixa que na área central. Já as máximas absolutas e as médias das máximas apresentam tendências mais variadas, com a temperatura na periferia do centro urbano nem sempre mais baixa que na estação urbana.

${ }^{1}$ Assumida aqui, de forma dinâmica, para cada hora de medição. 
Observa-se que, embora tais valores reflitam a situação local de aquecimento/resfriamento e as amplitudes térmicas de cada local, existem diferenças nos equipamentos empregados em ambas as estações. Além disso, os valores registradores não refletem as taxas de aquecimento/resfriamento que ocorrem hora a hora, apresentadas em termos de médias na Tabela 4 .

A Tabela 4 mostra a intensidade máxima da ilha de calor (noturna) $(\Delta \mathrm{Tu}-\mathrm{r}(\max ))$, a média das intensidades diárias e as diferenças médias de temperatura entre as duas estações, para cada período de análise.

Os dados mostram que a maior diferença registrada entre as temperaturas do ar medidas na Estação SIMEPAR e na Estação Ecoville ocorre no período diurno em razão de ganhos radiantes diferenciados nas duas estações durante o dia. O padrão, porém, não se mantém para as diferenças médias, que mostram a existência de uma pequena ilha de frescor na área urbana. Com relação aos dados noturnos, período durante o qual os ganhos solares não estão presentes, mas apenas o calor armazenado nas superfícies do entorno e as trocas convectivas, nota-se maior consistência e menor variação nos resultados. Nesse caso, o efeito do albedo é inexistente, e apenas o calor retido pelos materiais durante o dia é cedido ao meio, aquecendo o ar circundante.

Nota-se também que a máxima intensidade da ilha de calor ocorre no período de verão, mais especificamente em 2 de fevereiro de 2013.

A Tabela 5 refere-se ao efeito observado nos graus de conforto/ desconforto externo, conforme o procedimento apresentado na seção anterior (Procedimento adotado para análise de graus de conforto/desconforto térmico). A integração das diversas variáveis microclimáticas em um modelo de conforto, expresso em categorias de sensação térmica (frio, conforto e calor), acrescenta um elemento adicional à análise da ilha de calor, a qual leva em consideração apenas a temperatura do ar (KRÜGER et al., 2012). O modelo de predição de sensação térmica, agrupada segundo as três categorias citadas acima (Grupo 1: desconforto para o frio; Grupo 2: conforto; e,

Tabela 2 - Moradias monitoradas na Vila Tecnológica de Curitiba (DUMKE, 2002).

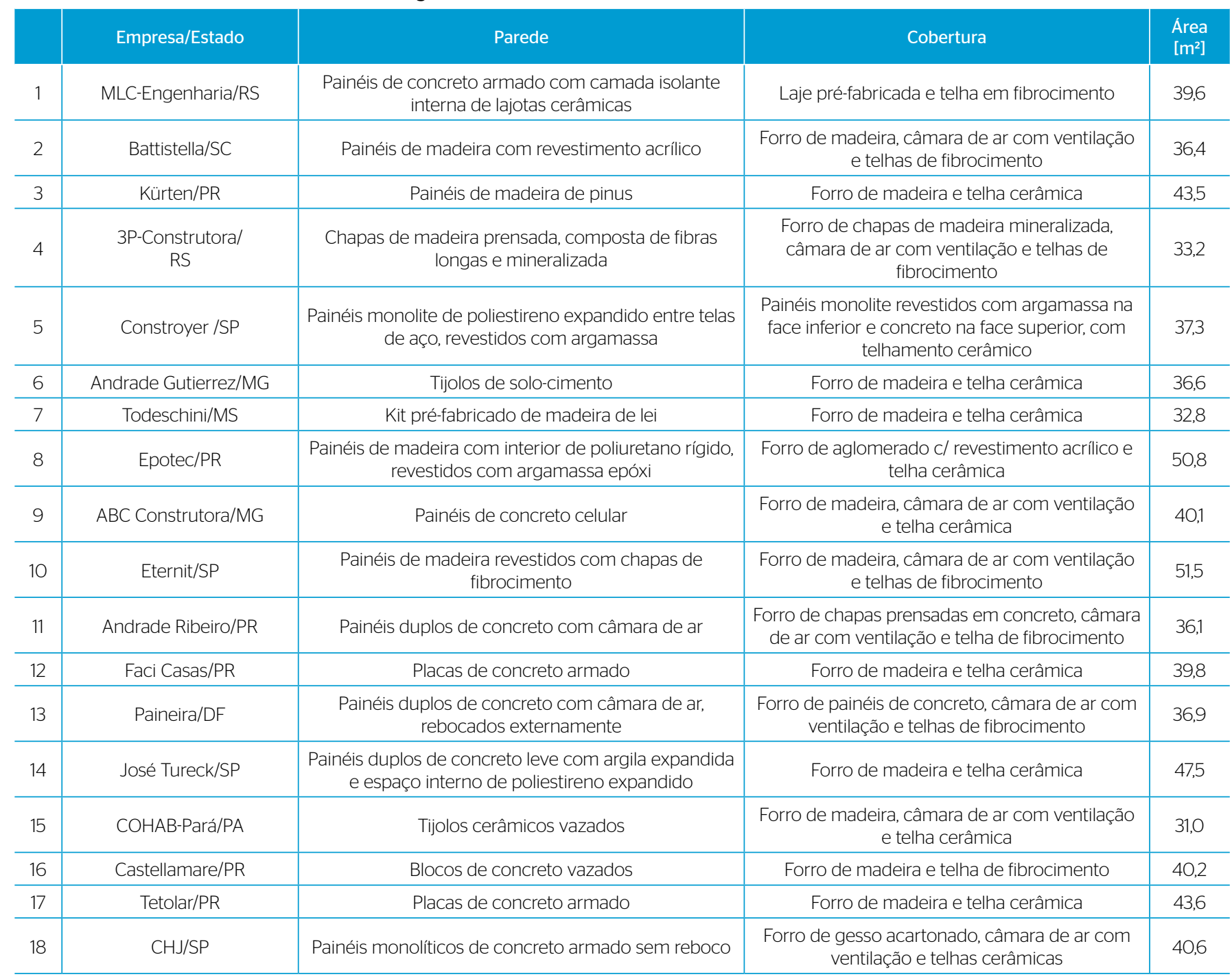


Grupo 3: desconforto para o calor), foi aplicado às variáveis climáticas monitoradas em cada estação. Os mesmos períodos foram adotados para a análise dos percentuais de horas em cada categoria, sendo apresentadas na Tabela 5 as diferenças nesses percentuais, para os períodos diurno e noturno, entre a Estação UFPR (urbana) e a Estação Ecoville (rural), em cada situação.

As diferenças percentuais entre níveis de conforto/desconforto foram calculadas para a condição urbana relativamente à condição rural. Dessa forma, a diferença máxima encontrada em termos de redução do desconforto por frio na área urbana (12\%, valor negativo) é verificada no verão e no período noturno, sendo acompanhada por um correspondente aumento da situação de conforto (11\%, valor positivo) e minimamente da situação de desconforto por calor ( $1 \%$, valor positivo). Nota-se também que, em todas as situações, a condição urbana apresenta redução do desconforto por frio (Grupo 1) à noite, confirmando a tendência da formação de ilha de calor noturna. Durante o dia, em razão do efeito combinado das diversas variáveis e considerando a presença da radiação solar, não se evidencia uma tendência, sendo o efeito da localização urbana mais aleatório.

A Tabela 6 refere-se ao efeito observado nos graus de conforto/desconforto interno nas moradias avaliadas, conforme o procedimento apresentado na seção anterior (Procedimento adotado para análise de graus de conforto/

Tabela 3 - Temperaturas mínimas absolutas, máximas absolutas e médias (méd) obtidas nas estações SIMEPAR (adotada como urbana) e Ecoville (adotada como rural).

\begin{tabular}{l|c|c|c|c|c}
\multirow{2}{*}{ Situação } & $\begin{array}{c}\text { Tmin } \\
\text { (abs) }\end{array}$ & $\begin{array}{c}\text { Tmax } \\
\text { (abs) }\end{array}$ & $\begin{array}{c}\text { Tmin } \\
\text { (méd) }\end{array}$ & $\begin{array}{c}\mathrm{T} \\
\text { (méd) }\end{array}$ & $\begin{array}{c}\text { Tmax } \\
\text { (méd) }\end{array}$ \\
\cline { 2 - 6 } Verão (Rural) & ${ }^{\circ} \mathrm{C}$ & ${ }^{\circ} \mathrm{C}$ & ${ }^{\circ} \mathrm{C}$ & ${ }^{\circ} \mathrm{C}$ & ${ }^{\circ} \mathrm{C}$ \\
\hline Inverno (Rural) & 12,2 & 32,4 & 16,7 & 20,4 & 25,7 \\
\hline Primavera (Rural) & 4,0 & 30,2 & 11,2 & 15,7 & 21,1 \\
\hline Outono (Rural) & 2,7 & 34,3 & 15,1 & 19,2 & 24,8 \\
\hline Ano (Rural) & 2,7 & 34,5 & 13,4 & 16,7 & 21,1 \\
\hline Verão (Urbana) & 11,7 & 32,2 & 17,2 & 20,7 & 25,6 \\
\hline Inverno (Urbana) & 4,4 & 31,4 & 11,1 & 15,8 & 21,6 \\
\hline Primavera (Urbana) & 3,4 & 33,8 & 15,4 & 19,4 & 24,6 \\
\hline Outono (Urbana) & 5,1 & 29,6 & 13,7 & 17,1 & 21,6 \\
\hline Ano (Urbana) & 3,4 & 33,8 & 14,9 & 18,7 & 23,8 \\
\hline
\end{tabular}

desconforto em ambientes internos). Embora a existência do efeito de ilha de calor em Curitiba, com base nos níveis de conforto obtidos para ambientes externos, traga consigo uma queda no desconforto por frio na área urbana, tal resultado não se aplica necessariamente ao ambiente interno. Os dados monitorados no interior das moradias populares (DUMKE, 2002) apresentaram temperaturas internas mais altas que as externas, tanto no verão como no inverno, sendo a intensidade dessa elevação dada em função da moradia monitorada (Figura 2).

Tabela 5 - Diferenças em percentuais de horas entre a Estação SIMEPAR (adotada como urbana) e a Estação Ecoville (adotada com rural) nos três grupos, para cada período.

\begin{tabular}{l|c|c|c|c|c|c}
\multirow{2}{*}{} & \multicolumn{2}{|c|}{ Grupo 1: Frio } & \multicolumn{2}{c|}{$\begin{array}{c}\text { Grupo 2: } \\
\text { Conforto }\end{array}$} & \multicolumn{2}{c}{ Grupo 3: Calor } \\
\cline { 2 - 7 } & Dia & Noite & Dia & Noite & Dia & Noite \\
\hline Período completo & 0 & -7 & 0 & 6 & 0 & 1 \\
\hline Verão & -1 & -12 & 0 & 11 & 0 & 1 \\
\hline Inverno & -1 & -3 & -1 & 1 & 2 & 2 \\
\hline Primavera & 2 & -8 & 2 & 6 & -4 & 1 \\
\hline Outono & 1 & -1 & -3 & 0 & 1 & 1 \\
\hline
\end{tabular}

Figura 2 - Elevação da temperatura média interna (noturna) em relação à externa nas 18 moradias avaliadas para os períodos de verão e de inverno conforme monitoramento térmico.

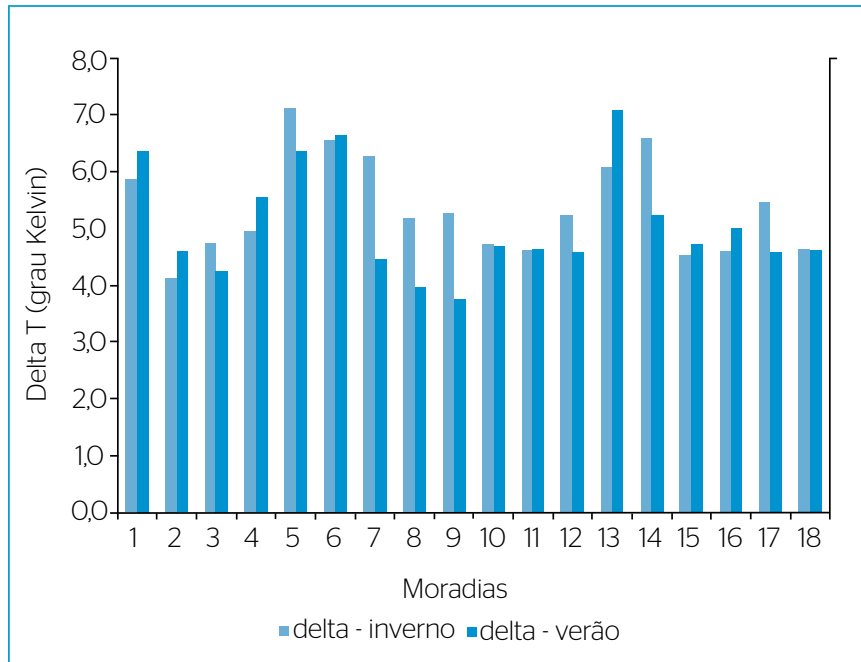

Tabela 4 - Intensidade da ilha de calor $(\Delta \operatorname{Tu}-\mathrm{r}(\max ))$ e diferenças médias de temperatura, para diferentes períodos do ano.

\begin{tabular}{l|c|c|c}
\multirow{2}{*}{ Período completo (diurno) } & Intensidade da ilha de calor & Intensidade da ilha de calor & Diferença média horária \\
\cline { 2 - 4 } & $\left(\Delta \mathrm{T}_{\text {urr(max })}\right)-$ máximo absoluto & $\left(\Delta \mathrm{T}_{\text {ur(max })}\right)$ - média para o período & - \\
\hline Período completo (noturno) & 11,5 & - & $-0,3$ \\
\hline Verão & 5,3 & 1,2 & 0,5 \\
\hline Inverno & 5,3 & 1,2 & 0,6 \\
\hline Primavera & 2,7 & 1,3 & 0,3 \\
\hline Outono & 5,1 & 1,2 & 0,6 \\
\hline
\end{tabular}


Para a série de dados monitorados internamente, assumiu-se um período noturno para verão (descontando-se as duas horas de período de transição entre o período diurno e noturno) das $20 \mathrm{~h}$ às $4 \mathrm{~h}$, e, para inverno, das 19 às $5 \mathrm{~h}$. Levando-se em conta a elevação média da temperatura interna para cada moradia em relação à temperatura externa nos dois períodos de monitoramento das moradias (Figura 2), podem-se estimar as temperaturas internas de cada edificação nos períodos de verão e inverno a partir dos dados externos coletados na estação SIMEPAR versus estação Ecoville. Com os dados para a área urbana e para a área periférica (rural), auferem-se os níveis de conforto resultantes (Tabela 6). Os valores da temperatura neutra (Tn) foram obtidos conforme o procedimento descrito na seção "Procedimento adotado para análise de graus de conforto/ desconforto em ambientes internos".

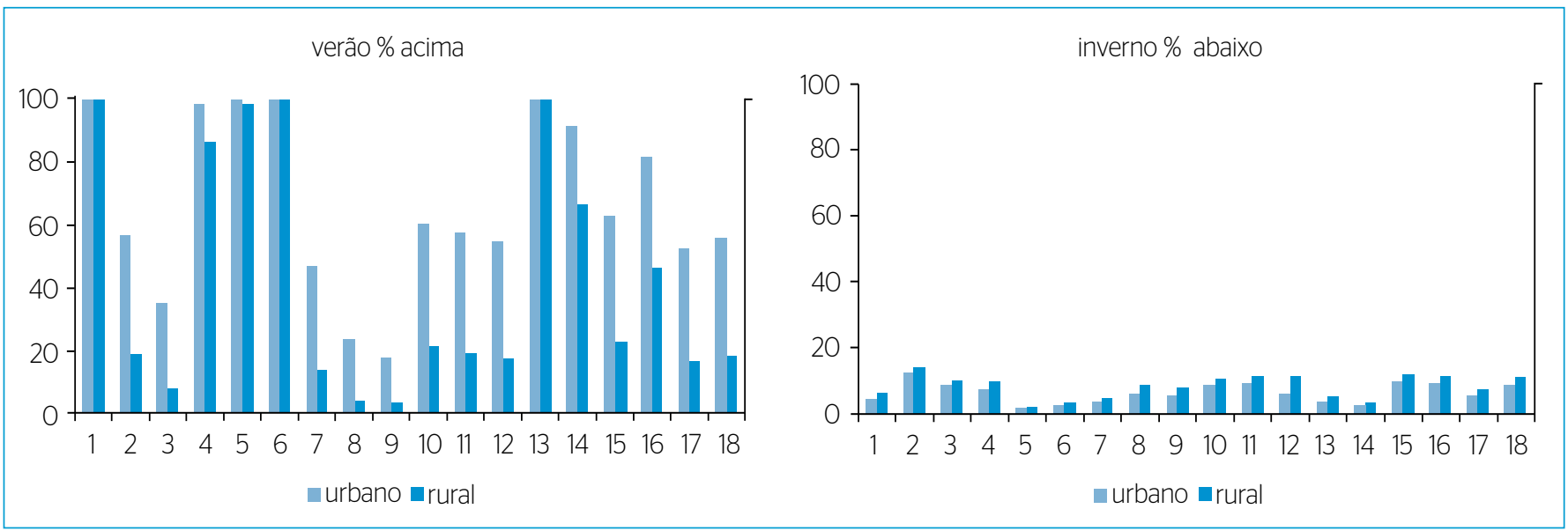

Figura 3 - Percentuais de tempo acima (A) e abaixo (B) de Tn (situação noturna) nas 18 moradias avaliadas nos períodos de verão e de inverno, projeções a partir das bases de dados.

Tabela 6 - Porcentagem de horas em desconforto nas 18 moradias (por frio ou calor) nos períodos de verão e inverno - estação urbana versus estação rural, projeções a partir das bases de dados.

\begin{tabular}{|c|c|c|c|c|c|c|c|c|}
\hline \multirow[b]{2}{*}{ Moradia } & \multicolumn{4}{|c|}{ Verão } & \multicolumn{4}{|c|}{ Inverno } \\
\hline & \multicolumn{2}{|c|}{$\begin{array}{l}\text { Porcentagem de tempo } \\
\text { acima de } \operatorname{Tn}(\%)\end{array}$} & \multicolumn{2}{|c|}{$\begin{array}{l}\text { Porcentagem de tempo } \\
\text { abaixo de } \operatorname{Tn}(\%)\end{array}$} & \multicolumn{2}{|c|}{$\begin{array}{l}\text { Porcentagem de tempo } \\
\text { acima de } \operatorname{Tn}(\%)\end{array}$} & \multicolumn{2}{|c|}{$\begin{array}{l}\text { Porcentagem de tempo } \\
\text { abaixo de } \operatorname{Tn}(\%)\end{array}$} \\
\hline 1 & 100 & 100 & 0 & 0 & 95 & 94 & 4 & 6 \\
\hline 2 & 57 & 19 & 43 & 81 & 88 & 86 & 12 & 14 \\
\hline 4 & 98 & 86 & 2 & 14 & 93 & 90 & 7 & 10 \\
\hline 5 & 100 & 98 & 0 & 2 & 98 & 98 & 2 & 2 \\
\hline 6 & 100 & 100 & 0 & 0 & 97 & 96 & 3 & 4 \\
\hline 7 & 47 & 14 & 53 & 86 & 96 & 95 & 4 & 5 \\
\hline 8 & 24 & 4 & 76 & 96 & 94 & 91 & 6 & 9 \\
\hline 12 & 55 & 18 & 45 & 82 & 94 & 92 & 6 & 8 \\
\hline 13 & 100 & 100 & 0 & 0 & 96 & 95 & 4 & 5 \\
\hline 14 & 91 & 67 & 9 & 33 & 97 & 96 & 2 & 4 \\
\hline 15 & 63 & 23 & 37 & 77 & 90 & 88 & 10 & 12 \\
\hline 16 & 81 & 47 & 19 & 53 & 91 & 89 & 9 & 11 \\
\hline 17 & 53 & 17 & 47 & 83 & 94 & 93 & 5 & 7 \\
\hline 18 & 56 & 19 & 44 & 81 & 91 & 89 & 9 & 11 \\
\hline Média & 66 & 42 & 34 & 58 & 93 & 92 & 6 & 8 \\
\hline $\begin{array}{l}\text { Diferença relativa (estação } \\
\text { urbana - estação rural) }\end{array}$ & \multicolumn{2}{|c|}{24} & \multicolumn{2}{|c|}{-24} & \multicolumn{2}{|c|}{2} & \multicolumn{2}{|c|}{-2} \\
\hline
\end{tabular}


Um fator importante: na Figura 2, nota-se um diferencial da temperatura interna (noturna) das moradias em média ligeiramente maior no inverno do que no verão, com uma elevação relativa entre ambos de $0,4^{\circ} \mathrm{C}$ para o período frio, embora com variações entre as moradias. Tal fato se relaciona em grande parte ao uso reduzido de ventilação natural e ao aumento da produção interna de calor no período frio, o que mostra algum potencial adaptativo dos ocupantes (HOES et al., 2009). Esse potencial adaptativo dos ocupantes traz implicações no desempenho das moradias, quando se consideram as duas estações do ano, supondo-se localização urbana versus rural.

Pela Tabela 5 nota-se que a diferença relativa (localização urbana versus rural) entre porcentagem de tempo (horas) acima da temperatura neutra ( $\mathrm{Tn}$ ) é significativamente maior no verão que no inverno. Enquanto no verão, em média, há um aumento de $24 \%$ das horas com temperatura interna acima de Tn, acarretando situação de desconforto por calor, no inverno há uma redução do percentual de horas em frio, porém bem mais discreto, de $2 \%$ das horas.

Nota-se, dessa forma, que um aumento nos níveis de conforto no ambiente externo com a diminuição das horas de frio decorrente de uma localização urbana poderia gerar desconforto térmico dentro de casa durante o período noturno. Os efeitos disso podem acarretar a perda da qualidade do sono. Peeters et al. (2009) discutem a qualidade do sono em relação à temperatura de dormitórios, listando uma série de autores que apontam para uma queda na qualidade do sono para temperaturas elevadas em dormitórios.

O efeito da ilha de calor nos ambientes internos traz um aumento no desconforto por calor no verão superando percentualmente, e em grande desvantagem, a redução do desconforto por frio no período de inverno. A diferença média relativa é maior no verão que no inverno, fato que se relaciona diretamente com a maior intensidade da ilha de calor nessa estação e, indiretamente, ao comportamento térmico das edificações avaliadas nos dois períodos (Figura 2). Dessa forma, nota-se que a ilha de calor pode trazer complicações no desempenho térmico de edificações mais acentuadamente no verão que no inverno (Figura 3). Nota-se, além disso, que todas as moradias apresentam de forma consistente um aumento nos níveis de desconforto interno por calor (no período de verão) e uma redução no desconforto por frio (no inverno) na área urbana. Considerando que as Equações 1 a 4 para obtenção da temperatura de neutralidade térmica, a partir da qual foram calculados esses percentuais, foram utilizadas de forma conservadora (valores imediatamente abaixo e acima de Tn caracterizando desconforto ${ }^{2}$ ), supõe-se que as diferenças em termos de desconforto por frio na área urbana versus área rural se anulem no período de inverno. Tomando-se como referência, dentre os diversos sistemas construtivos, a moradia 15, padrão $\mathrm{COHAB}$, uma edificação mais convencional com parede de tijolos cerâmicos, coberta por telhas e forro de madeira, nota-se um incremento em $20 \%$ das horas com desconforto por calor na área urbana no verão.

\section{CONSIDERAÇÕES FINAIS}

Como implicação direta dos resultados encontrados, nota-se que, para Curitiba, a ilha de calor pode, sob determinadas condições (considerando-se o fato de se tratar da capital mais fria do país), serbenéfica, reduzindo o desconforto por frio no espaço externo. Entretanto, deve-se ressaltar que a ilha de calor pode significar um aumento no percentual de horas em situação de calor (Grupo 3); ainda que seja pequeno sob as condições medidas. Em condições urbanas de maior adensamento, tal aumento pode trazer situações de overheating interno. Para Curitiba, a partir da análise das implicações da ilha de calor em moradias populares, pôde-se verificar que o aumento relativo do desconforto por calor no verão é mais significativo que a redução do desconforto no período de inverno. Conclui-se ainda que o benefício térmico da ilha de calor com a redução do frio no inverno não compensa as consequências do incremento térmico e de aumento do desconforto externo e interno a edificações localizadas na área urbana quando em situações de verão.

${ }^{2} \mathrm{Na}$ aplicação de equações de regressão segundo o princípio de conforto adaptativo, são estipuladas faixas de aceitabilidade térmica (80 e $90 \%$ ), às quais correspondem variações para mais e para menos a partir da temperatura de conforto (De DEAR \& BRAGER, 2004), procedimento que não é adotado aqui.

\section{REFERÊNCIAS}

ASHRAE - AMERICAN SOCIETY OF HEATING, REFRIGERATING AND AIR-CONDITIONING ENGINEERS. (1993) Handbook of Fundamentals. Atlanta: ASHRAE. Cap. 24. p. 24.1-24.23.

DE DEAR, R.J. \& BRAGER, G.S. (2004) Thermal comfort in naturally ventilated buildings: revisions to ASHRAE Standard 55. Energy and Buildings, v. 34, p. 549-561.

DUMKE, E. (2002) Avaliação do desempenho térmico de sistemas construtivos da vila tecnológica de Curitiba como subsídio para o estudo de tecnologias apropriadas em habitação de interesse social.
Dissertação (Mestrado em Tecnologia) - Universidade Tecnológica Federal do Paraná, Curitiba, 2002.

(2007) Clima urbano/conforto térmico e condições de vida na cidade - Uma perspectiva a partir do Aglomerado Urbano da Região Metropolitana de Curitiba (AU-RMC). Tese (Doutorado em Meio Ambiente e Desenvolvimento) - Universidade Federal do Paraná, Curitiba.

EMMANUEL, R. \& KRÜGER, E.L. (2012) Urban heat island and its impact on climate change resilience in a shrinking city: The case of Glasgow UK. Building and Environment, v. 53, p. 137-149. 
GRIMMOND, C.S.B. (2011) London's urban climate: a historical and contemporary perspective. ESRC City weathers: meteorology and urban design 1950-2010. University of Manchester, Reino Unido (keynote).

HOES, P; HENSEN, J.L.M.; LOOMANS, M.G.L.C.; de VRIES, B.; BOURGEOIS, D. (2009) User behavior in whole building simulation. Energy and Buildings, v. 41 , p. 295-302.

INTERNATIONAL ORGANIZATION FOR STANDARDIZATION. (1995) ISO 10551: ergonomics of the thermal environment: assessment of the influence of the thermal environment using subjective judgment scales. Genebra.

KRÜGER, E.; DRACH, P.; EMMANUEL, R.; CORBELLA, O. (2012) Urban heat island and differences in outdoor comfort levels in Glasgow, UK. Theoretical and Applied Climatology, v. 112, p. 127-141.

LOMBARDO, M.A. (1985) Illha de Calor nas Metrópoles: o exemplo de São Paulo. São Paulo: Ed. Hucitec.

MENDONÇA, F. \& DUBREUIL V.R. (2005) Termografia de Superfície e Temperatura do Ar na RMC (Região Metropolitana de Curitiba/PR). Ra'e ga (UFPR), n. 9, p. 25-35.

MINELLA, F.O; RASIA, F; KRÜGER, E.L. (2011) Impactos microclimáticos do desenho urbano: estudos realizados em Curitiba. Ráe ga (UFPR), v. 21, p. 298-338.
OKE, T.R. (1978) Boundary Layer Climates. London, Methuen \& Co.

(2006) Initial guidance to obtain representative meteorological observations at urban sites. Genebra: WMO.

PEETERS, L.; DE DEAR, R.; HENSEN, J; D'HAESELEER, W. (2009) Thermal comfort in residential buildings: Comfort values and scales for building energy simulation. Applied Energy, v. 86, p. 772-780.

ROSSI, F. (2012) Proposição de metodologia e de modelo preditivo para avaliação da sensação térmica em espaços abertos em Curitiba. Tese (Doutorado em Tecnologia e Sociedade) Universidade Tecnológica Federal do Paraná, Curitiba.

SUGA, M. \& KRÜGER, E.L. (2009) Recommendations of Height Restrictions for Urban Canyons in Curitiba, Brazil. Journal of Asian Architecture and Building Engineering (Online), v. 8, p. 447-452.

SZOKOLAY, S.V. (1983) Arquitectura Solar: Realización y Proyectos a Escala Mundial. Editorial Blume. Barcelona.

UNITED NATIONS (ONU). DEPARTMENT OF ECONOMIC AND SOCIAL AFFAIRS, POPULATION DIVISION (2012) World Urbanization Prospects: The 2011 Revision, CD-ROM Edition. 